\title{
NISTIR 6516
}

\section{Internet Commerce for}

Manufacturing

\section{Activity Model}

Edward Barkmeyer

Manufacturing Systems

Integration Division

James Nell

Manufacturing Systems

Integration Division

Curtis Parks

Electricity Division

ICM Project

May 3, 2000
U.S. DEPARTMENT OF COMMERCE

Technology Administration

National Institute of Standards and Technology

Electronics and Electrical Engineering Laboratory Electricity Division

Gaithersburg, MD 20899

\section{NLT}

National Institute of Standards and Technology

Technology Administration, U.S. Deportment of Commerce

$\alpha$

100

.056

N0.6516 



\section{Internet Commerce for Manufacturing Activity Model}

Edward Barkmeyer

James Nell

Curtis Parks

ICM Project
U.S. DEPARTMENT OF COMMERCE

Technology Administration

National institute of Standards

and Technology

Electronics and Electrical Engineering Laboratory Electricity Division

Gaithersburg, MD 20899

May 2000

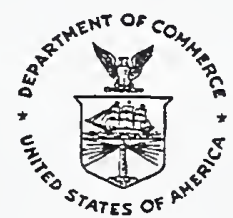

U.S. DEPARTMENT OF COMMERCE

William M. Daley, Secretary

TECHNOLOGY ADMINISTRATION

Dr. Cheryl L. Shavers, Under Secretary of Commerce for Technology

NATIONAL INSTITUTE OF STANDARDS AND TECHNOLOGY

Raymond G. Kammer, Director 



\section{Foreword}

Early in the development of the Internet Commerce for Manufacturing (ICM) project, the team felt that an "activity model" would be a distinct asset to the program. If such a model was sufficiently robust, there may be the possibility that the model itself could be used to key-link all of the elements of the project. Activity, or "function" models were a common element in many of the projects in both the Manufacturing Engineering Laboratory, and the Electronic Information Technologies Group of the Electronics and Electrical Engineering Laboratory. Further, a language standard was available; Federal Information Processing Standard, FIPS 183 "Integration Definition for Function Modeling (IDEF0)," which had been developed by (the former) NIST Computer Systems Laboratory.

\section{Executive Summary}

This paper describes the activity model as proposed for use in the Internet Commerce for Manufacturing (ICM), a project of the National Advanced Manufacturing Testbed program. This model will be used to identify those Internet-facilitated transactions as they are accomplished in the ICM Testbed. The model may also facilitate the visualization of the transactions developed by ICM. Where deemed appropriate, the model may serve to facilitate evaluation of the ICM business case. Finally, the model can be used to make recommendations for extensions of the ICM Architecture beyond the current industry domain.

The model is considered to be somewhat dynamic during the life of the ICM project. A partner to the ICM, the DARPA-funded Eccé (not necessarily an acronym), led by Intermetrics, Inc., offered a candidate activity model. To facilitate rapid access and changes, Intermetrics has agreed to participate in the ICM project by publishing on the Internet the ICM version of the model, and to periodically review changes for inclusion into the Eccé model. The Eccé model itself is presently found as a World Wide Web (Web) page at http://www.inmet.com/ecce/ActivityModel/.

\section{Introduction}

The model was selected following the ICM Scenario Workshops. It was refined and documented primarily for use in analyzing the ICM Testbed to Scenerio correlations. The model as shown is primarily a subset of the model [Reference: http://www.inmet.com/ecce/] developed for the DARPA Eccé project. In part, the Eccé model was selected because that project has the support of the Institute for Packaging Printed Circuits (IPC) and the Electronic Industries Association (EIA). Based on the Eccé work, the IPC is developing GenCAM; a CAD-to-CAM data transfer standard. Also based on the Eccé work, the EIA is developing an extension to Electronic Data Interchange Format (EDIF), to be called CAM-IM; an "intermediate Format" for printed wiring assemblies (PCA).

The Eccé model, however, covered most of the life cycle of a PCA, whereas the ICM work focused on the part of the life cycle which involves Internet communication between the contracting company, the board (PCB) fabricator, and the PCA assembly shop. Following the selection of the Eccé model by the ICM Model Team, and approval by the ICM team, the selected model portions were reviewed for completeness and compatibility with the ICM scenario description. These findings are described in the Introduction section. The functions, together with the Inputs, Controls, Outputs, and Mechanisms (ICOMs) are listed in the Activity Model section. The model sheets of interest are provided in Appendix A. 


\section{Activity Model}

The function model (an alternate term for "activity" model) is a hierarchical decomposition of steps required to complete a function or activity. Each function is represented as a rectangle on a model page. each function, by means of some mechanism, and subject to certain controls, transforms its input into output. The function transformation may be any combination of these four kinds of transform: form, state, time, and place.

The functions are "connected" by arrows called ICOMs (for Input, Output, Control, and Mechanism). The ICOMs represent either physical objects or data which may be tangible or intangible. The ICOMs which represent data are of primary interest to the ICM project. When the ICOM represents data, the functions to which a particular ICOM is attached identify the source or sink for the data. Taken together, the model elements may be viewed as a "map" of the transactions defined for the ICM implementation. A further advantage of the IDEF0-type model is the focus on what must occur; as opposed to the who or when aspects of the action.

The A-0 established the overall context of the model. More importantly, the A-0 supplies the ICOMs needed for all subsequent levels of decomposition. Under each function, the first occurrence of each ICOM together with the given definition is listed. Where the ICOM is associated with subsequent functions, the ICOM definition is referenced to the first occurrence.

Following the IDEF0 method described in FIPS 183, the top-level function, A-0, is listed. The selected model functions follow. The function numbers are in numeric order. The function numbers have been retained from the parent Eccé model. We recognize that the specified method of presenting an IDEF0 model is through the diagram pages. However, the indented-level form used in the Activity Model section provides a name-and-definition list more useful to the ICM project and project collaborators. We recognize that the on-line interactive presentation found at the URL listed in the Executive Summary may be more useful to the model reader.

NOTE: We have marked some ICOMS with "(part of)" where the ICOM consists of several data, and the particular data of interest are not specifically identified.

\section{A-0: Develop Electronic Assembly}

The process for establishing a Printed Board or Module (MCM, PCMCIA, etc.) Assembly from the original engineering goals to the final fully tested and functional product.

Inputs:

Product Specification: A document that describes the product being manufactured including physical, environmental, and performance requirements.

Raw and Base Materials: The raw and base materials used to fabricate printed boards which are usually described by the physical description data provided as part of the Engineering information.

Outputs:

Assembly Management Information: Documentation certifying that assembly meets customer requirements and expectations.

Completed Assembly: The completed board with all components attached, conformally coated and tested, and ready for shipping.

Coupon/Test Assembly: Specific quality assurance coupons used to verify that the assembly performs as intended or that assembly processes have not degraded the components, Controls: mounting structures, or their interface. 
Process Capability: The capability of processes and equipment described in terms of their ability to maintain precision or other physical characteristics needed by the final board or final assembly.

Preferred Supplier: Those suppliers that have been identified as being able to provide laminate, copper, or other resin based or ceramic based materials used to make a printed board or Mechanisms: interconnecting structure on time, with the right quality, and at a reasonable price.

CAD: Computer Aided Design

CAM: Computer Aided Manufacturing

MRP System: The system used by either the manufacturer, the customer, or the assembler for release of materials to the production floor.

\section{A3: Perform Administrative Functions}

The customer activity to establish the methodology of how to work with suppliers (board fabrication, assembly, etc.), develop the quotation material with the aid of engineering and design, establish the delivery schedule, contractual agreements, and purchasing liaisons for consignment assembly, and monitor the progress in order to develop supplier feed-back and re-use purchasing, and acquire management information.

Inputs:

Design/ Layout Data: The description of the drawing types, the format, the restrictions or relationships specified by the customer regarding notes or other requirements controlling the preparation of physical or electronic drawing formats.

Drawing Definition: The hard copy or electronic descriptions detailing a printed board, printed board assembly, specific components or other characteristics needed to procure or reprocure a product so that the intended form, fit, and function properties have the same characteristics no matter when or where the parts are purchased.

Assembly Certificate of Compliance: Documentation certifying that assembly meets customer requirements and expectations.

Management Information: Includes Fabrication Management Information and Assembly Management Information. (from A4 and A5)

Fabrication Certification of Compliance: Documentation certifying that the printed board meets customer requirements and expectations.

Supplier Performance Rating: A rating system that determines the ability of the supplier to provide high quality parts.

Outputs:

Customer Component/Board Consignment: Providing the assembly company with the components and boards on a consignment basis where the only services performed are that of placing and attaching the components to the bare board and performing electrical testing.

Completed Documentation: All documents including master drawing, schematics, specifications, assembly drawing, list of materials, and other details necessary to fully describe the product for procurement and re-procurement purposes.

Administrative Data: Quantity required, who is responsible, engineering point of contact, ship to data, delivery schedule, sender, receiver, user manuals, test vectors, E-proms, assembly number, ECO number, etc.

Configuration Management / Revision Control: Establishing the relationship between various modifications of a printed board assembly in order to make certain that the manufacturing sequences are building the right part with the right components.

\section{A32: Evaluate / Select Suppliers}

Inputs:

Quality Rating: (output of A354)

Outputs: 
Customer Component/Board Consignment: Providing the assembly company with the components and boards on a consignment basis where the only services performed are that of placing and attaching the components to the bare board and performing electrical testing. Administrative Data: (part of) A3 output

\section{A33: Initiate Contracts / Purchase Orders}

The process of preparing the appropriate purchase orders and contract relationships between the customer and the suppliers producing the printed boards and printed board assemblies, as well as establishing the correlation between these disciplines, and what necessary controls are required.

\section{A331: Establish Supplier List}

Activity of developing a list of preferred suppliers for printed board fabrication and printed board assembly, and any pre-operative/liaison activity that should take place between given manufacturers.

Inputs:

Configuration Management / Revision Control: (output of A31)

Quality Rating: (output of A354)

Contacts \& Preferred Suppliers: (output of A335)

Outputs:

Purchase Orders: Those documents used to order parts in the appropriate quantity, quality, and sequence as needed by the manufacturing and assembly operations.

Administrative Data: (part of) A3 output.

Parts Consignment: Those parts that are provided by the customer to the assembler on a consignment basis for attachment to the printed board assembly.

Turn-Key Responsibility: Determining who has responsibility within a turn-key operation as well as defining the relationship between customer, manufacturer or other suppliers; sometimes known as pass down requirements.

Configuration Control: The methodology used to maintain a level of understanding as to what parts are being built, or what parts and assemblies are in equipment that has been shipped or is in the field.

\section{A332: Initiate Component Procurement}

The activity of purchasing or drawing from inventory those electronic, electromechanical, and mechanical components needed to complete the assembly operation in those instances where components are supplied on a consignment basis to the assembly company.

Inputs:

Configuration Control: (output of A331)

Contacts \& Preferred Suppliers: (output of A335)

Completed Documentation: All documents including master drawing, schematics, specifications, assembly drawing, list of materials, and other details necessary to fully describe the product for procurement and re-procurement purposes.(output of $A 33, A 34$ )

Output:

Electronic Data (EDI): Data in electronic form used in commerce to specify or determine ordering information or other characteristics about a component, printed board or assembly. (tunneled - is not shown on higher-level functions)

Completed Documentation: (part of ) output of A33

\section{A333: Initiate Board Fabrication Procurement}

The activity of taking completed documentation and providing the information to the board fabricator, as well as establishing all liaisons necessary between board fabricator and assembly companies, and the feedback loop to the design facility should there be configuration, revision control, or other management issues.

Inputs: (same as A332)

Output: 
Completed Documentation: (part of) A33 output

Electronic Data (EDI): (part of) output of A332

A334: Initiate Assembly Procurement

The activity of taking completed documentation and providing the information to the assembly companies, as well as establishing all liaisons necessary between board fabricator and assembly companies, and the feedback loop to the design facility should there be configuration, revision control, or other management issues.

Inputs:

Parts Consignment: (output of A331)

Turn-Key Responsibility: (output of A331)

Configuration Control: (output of A331)

Completed Documentation: (part of) output of A33

Outputs:

Contacts \& Preferred Suppliers: (output of A335)

Completed Documentation: (part of) A33 output

Electronic Data (EDI): (part of) output of A332

A335: Establish Contacts \& Responsibility

The process of formally establishing the liaisons and contact points between fabricators, assemblers, and their customers, as well as any restrictions necessary in order to determine signoff or acceptance criteria, and includes both incoming inspection as well as on-site inspection responsibilities.

Inputs:

Configuration Control: (output of A331)

Outputs:

Completed Documentation: (part of) A33 output

Electronic Data (EDI): (part of) output of A332

\section{A34: Prepare Documentation}

The process of determining that complete information, scheduling and the processes necessary to produce, or re-procure, a printed board or printed board assembly are available and are consistent. The output of this activity is the complete documentation package, as well as any management or supplier performance rating information.

\section{A341: Develop Build Schedule}

The process of developing the needs for the delivery of the particular products in a sequence and volume necessary to produce the end-product assembly; also covers the fabrication of the board, procurement of components where necessary, and assembly schedule necessary to take printed board assemblies and incorporate them into the next level of the "box build" criteria.

Inputs:

Configuration Management / Revision Control: Establishing the relationship between various modifications of a printed board or printed board assembly in order to make certain that the manufacturing sequences are building the right part with the right components. (output of A31)

Work In-Progress Reports: Those reports that describe the details of information being passed on to other manufacturing disciplines; used to determine that work on the production floor Output: is moving in accordance with the schedule. (output of A345)

Product Delivery Schedule: The detailed schedule for providing a specific quantity of product, at a specific time, so that the product is available to the next manufacturing level or final customer.

\section{A342: Prepare Component Procurement Packages}


The process of organizing complete documentation for component procurement and information on component substitution capability, as well as possible MRP data, and where necessary provides the specification control drawings, or source control drawings needed for non-standard parts that are part of the printed board assembly.

Inputs:

Product Delivery Schedule: output of A341

Drawing Definition: The hard copy or electronic descriptions detailing a printed board, printed board assembly, specific components or other characteristics needed to procure or reprocure a product so that the intended form, fit and functional properties have the same characteristics no matter when or where the parts are purchased. (output of A2)

Design/Layout Data: Includes parts list, drawings, Gerber files, netlist, drill file(s), panelization, test requirements, test points, board/assembly separation, component placement, material requirements (such as laminate, solder mask, conductive material, surface finish, etc.), hole characteristics, board structure phototool requirements. (output of A2)

Assembly Turn-Key: (see output of A344) Outputs:

Completed Documentation: (part of) A34 output

\section{A343: Prepare Board Procurement Packages}

The process of organizing a complete description of the printed board documentation, the master drawing which includes all the physical requirements of the printed board, the phototool in both the electronic or documented form, as well as all testing or panelization specifications necessary to procure the printed board.

Inputs:

Product Delivery Schedule: (same as for A342) output of A341

Drawing Definition: (same as for A342) (output of A2)

Design/Layout Data: (same as for A342) (output of A2)

Assembly Turn-Key: (see output of A344)

Outputs:

Completed Documentation: (part of) A34 output

\section{A344: Prepare Assembly Procurement Packages}

The process of organizing the assembly drawings including all masking or special assembly requirements and coordinating those with the list of material or MRP data as well as any component substitution permitted in order to complete the fully tested and coated assembly operation.

Inputs:

Product Delivery Schedule: (same as for A342) output of A341

Drawing Definition: (same as for A342) (output of A2)

Design/Layout Data: (same as for A342) (output of A2)

Assembly Turn-Key: (see output of A344)

Outputs:

Completed Documentation: (part of) A34 output

Turn-Key Operation: Determining who has responsibility within a turnkey operation as well as defining the relationship between the customer, manufacturer or other suppliers; sometimes known as pass down requirements.

Assembly Turn-Key: Includes the contractual requirements that has an assembly company perform all acquisition including physical design, component and board procurement, assembly, box build, and delivery services.

\section{A345: Perform Schedule Monitoring}


The process of gathering supplier performance, work-in-progress reports, or any other management information necessary to improve the throughput, or manufacturing capability intended to provide the link among, and between, fabrication, assembly, and design.

Inputs:

Assembly Turn-Key: (see output of A344)

Product Delivery Schedule: (see output of A341)

Output:

Supplier Performance Rating: A rating system that establishes a quantative method to evaluate the performance for delivery, quality or other characteristics of a suppliers ability as a team member of a specific supply chain.

Management Information: (part of) output of A5

Work In-Process Reports: Those reports that describe the details of information being passed on to other manufacturing disciplines; used to determine that work on the production floor is moving in accordance with the schedule.

\section{A35: Do Quality Assessment}

The process of determining that the quality of the printed board or printed board assembly meets all the requirements of the documentation, through evaluation of the end-product (known as quality conformance testing), or establishing SPC (statistical process control) data that provides insight that the products shipped are consistent with the customer needs and expectations.

\section{A351: Perform On-Site Audits}

The process of having an inspector on-site at the fabrication or assembly facility and determining that the processes and procedures used by the fabricator or assembler are consistent with the endproduct needs of the customer.

Inputs:

Supplier Performance Rating: (see output of A345) Outputs:

Management Information: (part of) output of A5

Administrative Data: (part of) output of A3

Supplier Quality System: A system that determines the quality capabilities of the supplier or anyone within the supply chain.

\section{A352: Perform Incoming Evaluations}

The process of taking samples from those product (boards, components, assemblies) which are accepted into the production or end-product environment, and determining that the incoming shipment meets the requirements detailed in the documentation, as well as the performance stated therein.

Inputs:

Supplier Performance Rating: (see output of A345)

Assembly Certificate of Compliance: Documentation certifying that assembly meets customer requirements and expectations. (output of A54)

Fabrication Cert. of Compliance: Documentation certifying that the printed board meets Outputs: customer requirements and expectations. (output of A445)

Administrative Data: (part of) output of A3

Schedule of Delivery: The schedule on which product is intended to be delivered to the next stage or final customer; includes quantity, date, and time of delivery as well as packing information.

Supplier Feedback: The method of providing information back to the manufacturer or supplier indicating their performance so that the data can be used for future acquisitions. 
The process of determining the performance, both quality and delivery characteristics of specific suppliers to the end-user and developing a list of those companies that continue to provide the highest quality, on time, at a reasonable price.

Inputs:

Schedule of Delivery: (see output of A352)

Supplier Feedback: (see output of A352)

Supplier Performance Rating: (see output of A345)

Management Information: (part of) output of A5

Outputs:

Administrative Data: (part of) output of A3

Delivery Rating System: A system used to define the performance of suppliers, based on their capability to deliver product in the time and condition necessary to start the next operation.

\section{A354: Establish Preferred Supplier List}

The process of determining the performance, both quality and delivery characteristics of specific suppliers to the end-user and developing a list of those companies that continue to provide the highest quality, on time, at a reasonable price.

Inputs:

Supplier Quality System: (see output of A351)

Delivery Rating System: (see output of A353)

Supplier Feedback: (see output of A352)

Management Information: (part of) output of A5

Supplier Performance Rating: (see output of A345)

Outputs:

Administrative Data: (part of) output of A3

Quality Rating: A rating system that determines the ability of the supplier to provide high quality parts.

\section{A4: Fabricate Board(s)}

The activity of manufacturing the bare printed board from organic or non-organic base materials, including all conductive and non-conductive layers separated by reinforced or non-reinforced dielectric, and the metallic plating and coating that connect layers to one another, or protect the surface conductors, completely tested for electrical continuity and ready for component attachment. Inputs:

Administrative Data: (see output of A3)

Performance Requirements: Used for Environmental limits, Environmental / Functional Meantime-between-failure, testing, stress testing, qualification testing. (output of A1)

Functional Spec: The functions required to be performed by the assembly or circuits on the assembly or the assembly in conjunction with other assemblies. (output of A2)

Raw and Base Materials: The raw and base materials used to fabricate printed boards which are usually described by the physical description data provided as part of the Engineering information. (input to A-0)

Completed Documentation: (see output of A33, A34)

Assembly Design/Tooling Requirements: Includes manufacturing information, panelization, Controls: needs for the assembly, additional fiducials used. (output of A5)

Process Capability: (see A0)

Preferred Supplier: (see A0)

Mechanisms:

CAM: (see A0)

MRP System: (see A0)

Output: 
Assembly Photo Tools: Includes component placement images, solder paste images, glue dot inspection images, in-circuit test images, functional test images.

Fabrication Management Information: Includes process control data, yield information, and test specimens (coupons, boards, etc.)

Fabrication Certificate of Compliance: (see input of A352)

Coupon/Test Board: Specific quality assurance coupons used to verify that the printed board performs as intended or that manufacturing processes have not degraded the base materials precluding the board's intended use.

Completed Bare Board: The individual printed board completely process-ready for sending to the assembly operation.

\section{A41 Pre-Fabrication Engineering}

The function of determining that all materials, equipment and processes are capable of manufacturing the final bare board product in accordance with the engineering documentation and the functional requirements of the interconnecting system.

\section{A411Evaluate Board Material/Processes/Equipment Capability}

The function of determining that all materials, equipment and processes are capable of manufacturing the final bare board product in accordance with the engineering documentation and the functional requirements of the interconnecting system.

Inputs:

Coupon/Test Board: (see output of A4)

Supplier Innovations: (tunneled) Those processes or techniques used by a supplier that are slightly outside the scope of the normal processes, yet meet the characteristics of the final Outputs: assembly.

Approved Resources: Resources includes processes, materials, and equipment, and their Controls: capabilities as they apply to the fabrication and assembly.

Process Capability: (see Control of A0)

A412 Determine Board Build Configuration

Establishing the methodology of how the final board will be fabricated, including the sequence in which the various processes are performed and the material requirements needed at each stage of the manufacturing operation, i.e., copper-clad laminate, pre-preg, covercoat, solder mask. Inputs:

Assembly Management Information: (part of Management Information) Includes assembly process control data, yield data, assembly equipment performance/ capability, design for assembly information, and test specimens (coupons, boards, etc.), approved vendor list, data integrity errors, design for manufacturability reports, component availability, and testability reports.

Completed Documentation (see output of A3)

Functional Specification: (see output of A2)

Base Material Availability: The inventory or JT delivery schedule or the supplier material Outputs: delivery capability that is available in time to meet production schedules.

Fabrication Management Information: (see output of A4)

Board Test Data: Includes shorts / opens test, control impedance test, hipot test, environmental tests, coupon tests.

Board Fabrication Tooling Data: Includes drill data, photo tools, masks, routing data, scoring data, tool hole punching, coupon description, registration methods.

Build Board Configuration Document: The documentation describing the sequences necessary to build a particular board, panel or subpanel intended to provide operators with key issues as inspection or process control points. 
Board Process Sequencing: The fabrication process steps needed to manufacture a printed board in panel or subpanel format whether single, double or multilayered made of various Controls: materials and materials properties.

Preferred Base Material Supplier: Those suppliers that have been identified as being able to provide laminate, copper, or other resin based or ceramic based materials used to make a printed board or interconnecting structure on time, with the right quality, at a reasonable price.

Mechanisms:

A413 Create Board Process Traveler

The function of documenting the detailed steps required to manufacture the bare board, including materials needed, tooling requirements and set-ups, various inspection points, electrical test strategy, final coatings as well as packing and shipping instructions.

Inputs:

Fabrication Management Data: (see output of A4)

Board Test Data: (see output of A412)

Board Fabrication Tooling Data: (see output of A412)

Board Process Sequencing: (see output of A412)

Outputs:

Board Fabrication Process Traveler: The document that travels with the production order, describing materials, sequencing of various processes, testing requirements, timing and Controls: schedule, equipment, responsibility assignment, and quality inspections.

Mechanisms:

A414 Create Bare Board Test Fixture

The activity of determining the mechanical fixture requirements for electrical continuity testing, or software needed for flying probe testing, as well as all other test fixtures for special electrical function evaluations such as impedance control or insulation resistance measurements.

Inputs:

Fabrication Management Data: (see output of A4)

Board Fabrication Tooling Data: (see output of A412)

Functional Specification: (see input of A4)

Outputs:

Fixture Definition(s): The functions of component lead forming, board/array positioning, process chemistry protection, masking for coating, and electrical test fixture. This may Controls: include other fixtures such as process control data gathering fixtures.

Mechanisms:

A415 Establish Board Administration Requirements

The activity of determining the record keeping points of the manufacturing process, while the board is being produced, such as inspection points, sampling plans, Statistical Process Control (SPC), coupon destructive testing, plating bath evaluations, etc. needed to insure compliance with the customer detailed specifications or quality assurance requirements.

Inputs:

Fabrication Management Data: (see output of A4)

Build Board Configuration Document: (see output of A412)

Administrative Data: (see output of A3)

Outputs:

Board Build Commencement: The board fabrication start including production traveler, material release, and project monitoring tools.

Board Administrative Data: Includes timing, JIT, material acquisition, schedule of events, milestones, and reporting mechanisms.

Controls:

Base Material Availability: (see input of A412) 
Mechanisms:

\section{A42 Material Acquisition and Scheduling}

The activity of assembling the material, inventory, hard and soft tools, and any other information related to the material content of the printed board fabrication that must be available at the time of producing the printed board, including phototools and special test or masking fixtures.

Inputs:

Board Build Commencement: (see output of A415)

Fixture Definition(s): (see output of A414)

Board Fabrication Tooling Data: (see output of A412)

Board Administrative Data: (see output of A415)

Outputs:

Board Fabrication Process Traveler: (see output of A413)

Assembly Photo Tools: (see output of A4)

Continuity Test Fixture/Data: Open and short testing data of the bare printed board and the fixtures that determine the methodology and positioning of test probes.

Fabrication Management Information: (part of output of A4)

Base Material: Includes copper clad laminate, unreinforced laminate (flex), copper foil (Electrodeposited or wrought), prepreg("B" stage), cover coat.

Fabrication Photo Tools: Includes conductive images, coating images, legend images, inspection images.

Other Materials: Includes solder mask, legend ink, tooling pins, drills, router bits, scoring Controls: blades, punch and die, metal core, entry/exit material for drilling, caul plates.

Base Material Availability: (see input of A412)

Mechanisms:

MRP System: (see A0)

\section{A42.1 Aquire Base Materials}

The process of determining the in-house base material (laminate, copper, pre-preg) needed to fabricate the printed board, as well as the issuing of long term purchase orders that will satisfy justin-time delivery schedules.

Inputs:

Board Administrative Data: (see output of A415)

Board Build Commencement: (see output of A415)

Purchase Order Confirmation: (tunneled) The details necessary to describe the characteristics of a purchase order and the information contained therein.

Outputs:

Board Fabrication Process Traveler: (see output of A413)

Base Material: (see output of A42)

Fabrication Management Information: (part of output of A4)

Purchase Orders: (tunneled) Those documents used to order parts in the appropriate quantity, Controls: quality, and sequence as needed by the manufacturing and assembly operations.

Base Material Availability: (see input of A412)

Mechanisms:

MRP System: (see A0)

\section{A422 Develop Hard \& Soft Tooling}

The process of establishing the fixture and tooling requirements needed for board fabrication related to the production master, step-and-repeat masters, production floor photo tools, as well as test fixtures or board routing/scoring in either documented description or electronic form. Inputs:

Board Build Commencement: (see output of A415)

Purchase Order Confirmation: (see input to A421) 
Board Administrative Data: (see output of A415)

Assembly Design/Tooling Requirements: (see input to A4)

Fixture Definition: (see output of A414)

Board Fabrication Process Traveler: (see output of A413)

Outputs:

Board Fabrication Tooling Data: (see output of A412)

Purchase Orders: (part of output of A421)

Assembly Photo Tools: (see output of A4)

Fabrication Photo tools: (see output of A42)

Continuity Test Fixture/Data: (see output of A42)

Fabrication Management Information: (part of output of A4)

Controls:

Mechanisms:

MRP System: (see AO)

\section{A423 Acquire Auxillary Materials}

The activity of analyzing all requirements for the printed board fabrication that have not already been covered in the base material or hard and soft tooling acquisitions such as drill and router bits, etching material, caul plates preparation materials, solder mask, strippers, etching chemistry, etc. Inputs:

Board Build Commencement: (see output of A415)

Purchase Order Confirmation: (tunneled; see input to A421)

Board Fabrication Process Traveler: (see output of A413)

Board Fabrication Tooling Data: (see output of A412)

Board Administrative Data: (see output of A415)

Outputs:

Purchase Orders: (part of output of A421)

Fabrication Management Information: (part of output of A4)

Other Materials: (see output of A42)

Controls:

Mechanisms:

MRP System: (see A0)

\section{A43 Fabricate Board}

The process of converting single image design data into multiple images on a full or sub-panel and completing all fabrication processes necessary to build the specific board type required by the customer.

Inputs:

Board Build Commencement: (see output of A415)

Base Material: (see output of A42)

Fabrication Photo Tools: (see output of A42)

Other Materials: (see output of A42)

Board Fabrication Tooling Data: (see output of A412)

Board Administrative Data: (see output of A415)

Board Fabrication Process Traveler: (see output of A413)

Raw and Base Materials: (see input of A4)

Outputs:

Coupon/Test Board: (see output of A4)

Fabrication Management Information: (part of output of A4)

Bare Board: The unpopulated board in several configurations: Individual single board, Controls: subpanel assembly array, or a full panel. After test, this may include packing material.

Mechanisms: 


\section{A44 Post Fabrication Activities}

The process of testing coupons and evaluating the performance of the completed printed board through all of its various processes in order to ascertain that it meets the customer's requirements; includes all forms of visual, physical, electrical, environmental, and stress testing, as well as providing certificates of compliance to show the customer that the delivered product meets all requirements indicated in the documentation.

Inputs:

Board Test Data (see output of A412)

Continuity Test Fixture/Data: (see output of A42)

Coupon/Test Board: (see output of A4)

Bare Board: (see output of A43)

Board Fabrication Tooling Data: (see output of A412)

Board Administrative Data: (see output of A415)

Board Fabrication Process Traveler: (see output of A413)

Performance Requirements: (see input to A4)

Outputs:

Fabrication Management Information: (part of output of A4)

Fabrication Certificate of Compliance: (see input of A352)

Completed Bare Board: The individual printed board completely process-ready for sending to Controls: the assembly operation.

Mechanisms:

\section{A441 Do Post-Fabrication Operations}

The process of scheduling the details necessary for determining that the completely manufactured printed board or subpanel is consistent with the customer requirements and meets the delivery and packaging schedules, as well as the preparation of all information necessary to characterize the completed printed board as to its capability and performance in the end-product.

Inputs:

Bare Board: (see output of A43)

Board Administrative Data: (see output of A415)

Continuity Test Fixture/Data: (see output of A42)

Board Fabrication Tooling Data: (see output of A412)

Outputs:

Board Administrative Data: (see output of A415)

Fabrication Management Information: (part of output of A4)

Controls:

Bare Board: (see output of A43)

Mechanisms:

\section{$\underline{\mathrm{A} 442}$}

The activity of taking bare printed boards or printed board subpanels and submitting them to electrical testing to determine that there are no opens or shorts in the circuitry, and includes special electrical tests that can determine impedance control or high frequency capability of the printed board circuitry for a single conductor or determin that the correct layer spacing exists between conductive planes.

Inputs:

Bare Board: (see output of A43)

Continuity Test Fixture/Data: (see output of A42)

Board Fabrication Tooling Data: (see output of A412)

Board Fabrication Process Traveler: (see output of A413)

Board Test Data: (see output of A412)

Outputs:

Fabrication Management Information: (part of output of A4) 
Controls:

Fully Tested Board: A completely tested unpopulated board that functions as intended proving that there are no opens or shorts and that any impedance or high speed conditions are met.

Mechanisms:

A443 The activity of performing functional testing to determine that the bare printed board functions as intended, both electrically and mechanically, and includes such tests as flatness (bow and twist), dimensional checks, hi-pot testing, thermal cycling, or any other environmental test necessary to stress the board to ensure that it is capable of going through the Inputs: assembly processes and will function in the field.

Fully Tested Board: (see output of A442)

Bare Board: (see output of A43)

Board Test Data: (see output of A412)

Board Fabrication Process Traveler: (see output of A413)

Performance Requirements: (see input to A4)

Coupon/Test Board: (see output of A4)

Outputs:

Fabrication Management Information: (part of output of A4)

Controls:

Mechanisms:

A444 The activity of preparing a board that has been fully tested in accordance with the fabrication plan and adding an organic protective surface (OSP) coating, needed to protect exposed copper prior to the assembly, as the last process of the fabrication prior to shipping to Inputs: the customer.

Fully Tested Board: (see output of A442)

Board Fabrication Process Traveler: (see output of A413)

Outputs:

Fabrication Management Information: (part of output of A4)

Completed Bare Board: The individual printed board completely process-ready for sending to Controls: the assembly operation.

Mechanisms:

A445

The activity of taking boards that have been completely tested, cleaned, coated with OSP where necessary, and organizing them into specific sets where the boards are separated as necessary or packaged in groups as specified by the customer, including all serialization necessary to maintain traceability of the products being shipped.

Inputs:

Completed Bare Board: (see output of A444)

Board Fabrication Process Traveler: (see output of A413)

Outputs:

Fabrication Management Information: (part of output of A4)

Fabrication Certificate of Compliance: (see input of A352)

Completed Bare Board: (see output of A444)

Controls:

Mechanisms:

\section{A5: Assemble Board(s)}


The process of taking electronic, electromechanical, and mechanical components and assembling them to a printed board or interconnecting structure in order to produce a complete assembly, ready to be incorporated into an electronic equipment or box, and where necessary, to provide the appropriate cabling that establishes the link between the assembly, other assemblies, and the hardware in the enclosing structure; includes the placing and attachment of components, test, verification, burn-in, reliable test, coating, inspection, and shipping.

Inputs:

Completed Documentation: (see output of A33, A34)

Assembly Photo Tools: (see output of A4)

Fabrication Management Information: (see output of A4)

Design Layout Data*: (see input of A3)

Customer MRP Data: That data provided by the customer using their Material Resource

Planning System to specify those components or products that are defined in the

customer's MRP system. May also provide data for component substitution. (output of A2)

Performance Requirements: (see input of A4)

Functional Spec: (see input of A4)

Fabrication Certificate of Compliance: (see input of A352)

Coupon/Test Board: (see output of A4)

Completed Bare Board: (see output of A4)

Controls:

Process Capability: (see A0)

Preferred Supplier: (see A0)

Mechanisms:

CAM: (see A0)

MRP System: (see A0)

Outputs:

Assembly Certificate of Compliance: (see output of A-0)

Completed Assembly: (see output of A-0)

Coupon/Test Assembly: (see output of A-0)

*NOTE (from Plexus presentation): ICOM "Design/Layout Data" includes most of the data needed for fabrication. Other data is needed at appropriate times:

At RFQ, shop wants: dimensions, hole count, smallest hole size, layer count, BOM, AVL, and drawings in HPGL or DXF.

At Mfr\&Test shop wants: above, plus all Gerber ${ }^{\mathrm{TM}}$ layers, CAM in CAD native, and drill data.

\section{Recommendations for Further Research}

The ICM project is similar in scope to some of the in-work initiatives in the National Electronics Manufacturing Initiative (NEMI) organization. The model presented is expected to contribute to various modeling efforts within NEMI activities. As such, the model will likely increase in both quality and visibility. The possible use of the model as a means of examining the emerging NEMI roadmap is open to exploration. The authors also plan to evaluate the completeness of the scope of the ICM project itself. For the latter application, possible presentation methods will be explored using Web pages and links. 
Future ICM modeling is expected as process or flow models and data models. The activities defined herein are expected to identify the content and uses of elements of the remaining project models. 


\section{Appendix A}

\section{Activity Model Diagrams}

NOTE: These diagrams represent a specifically selected subset of the ECCE Project model which have been tailored for the ICM project. 


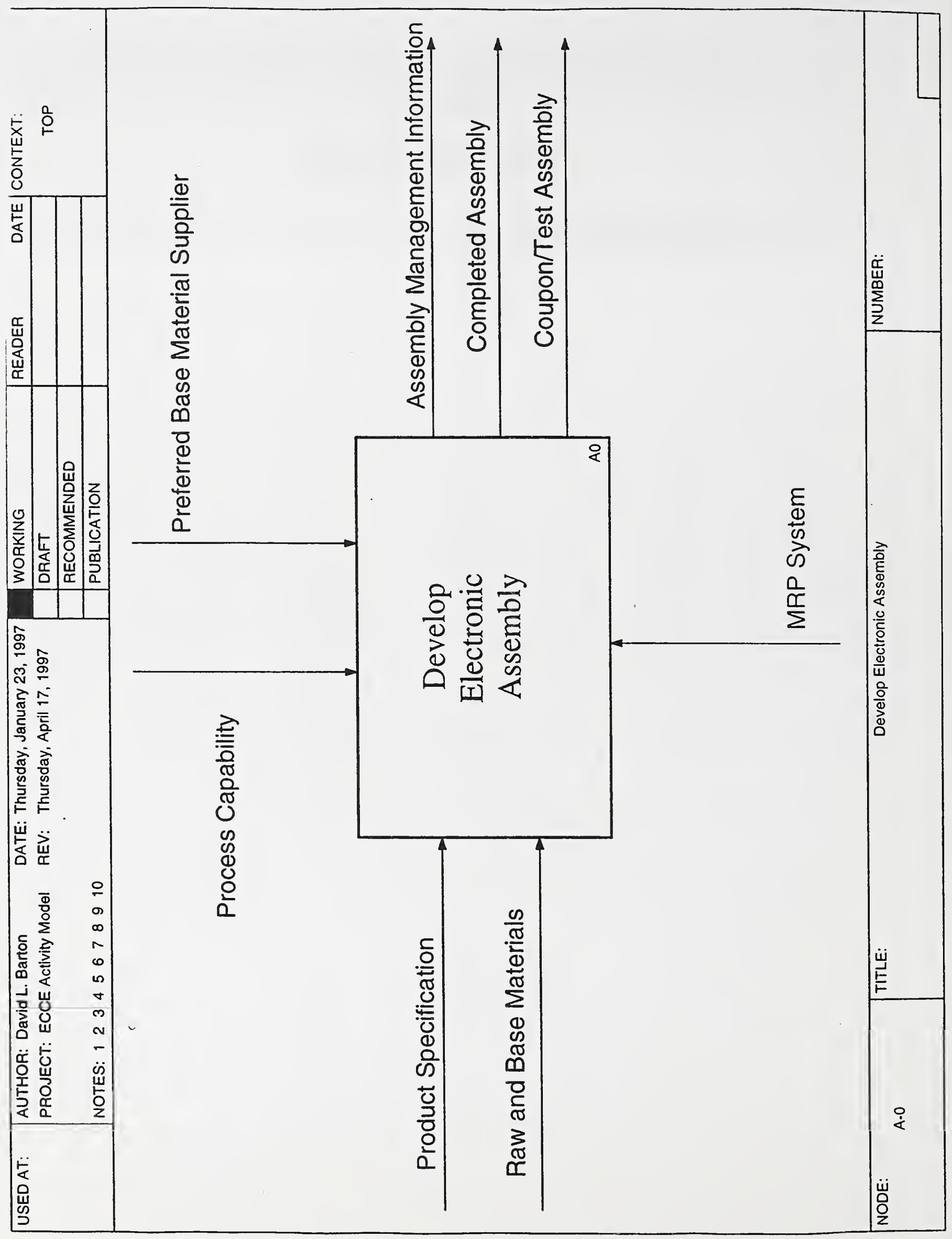




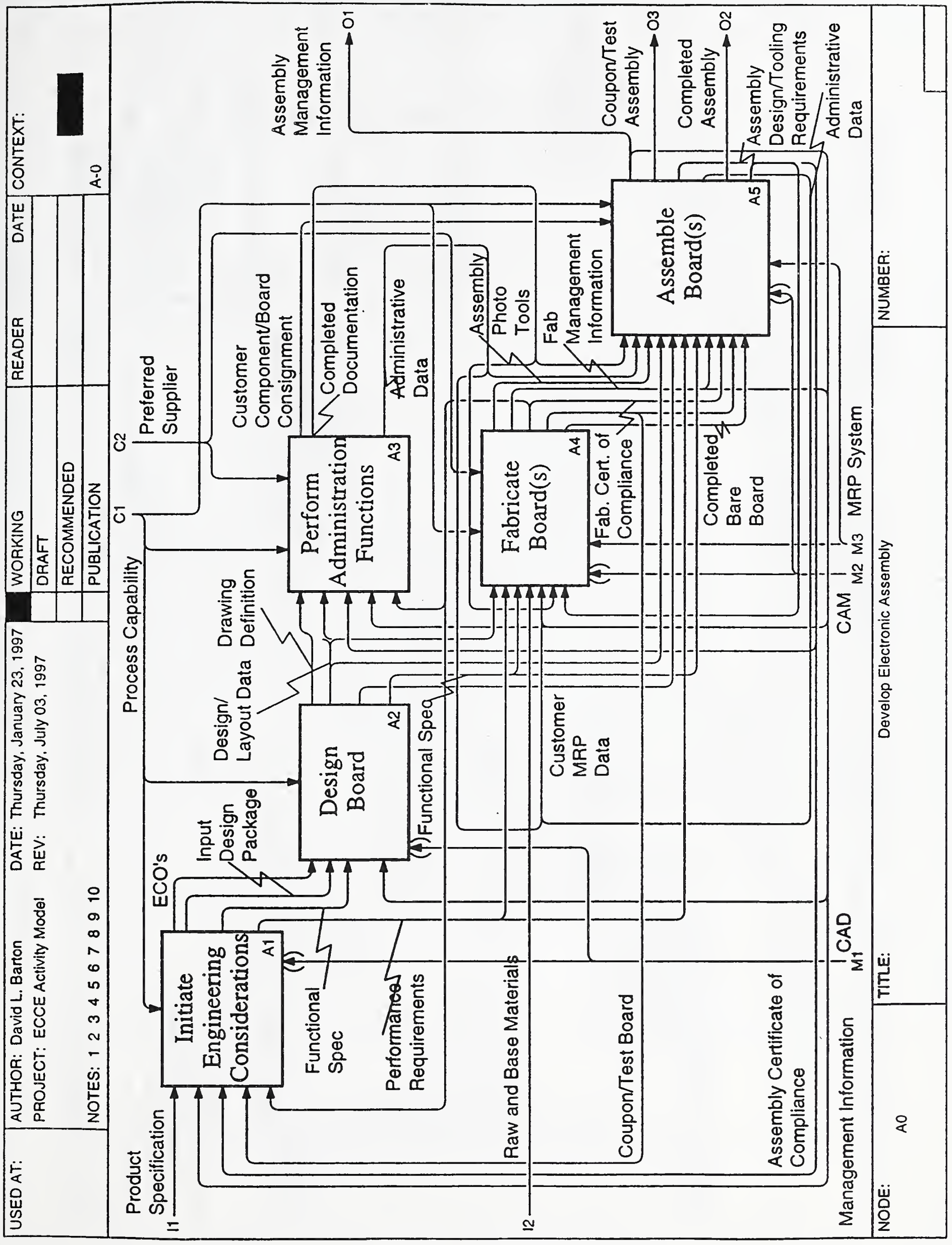




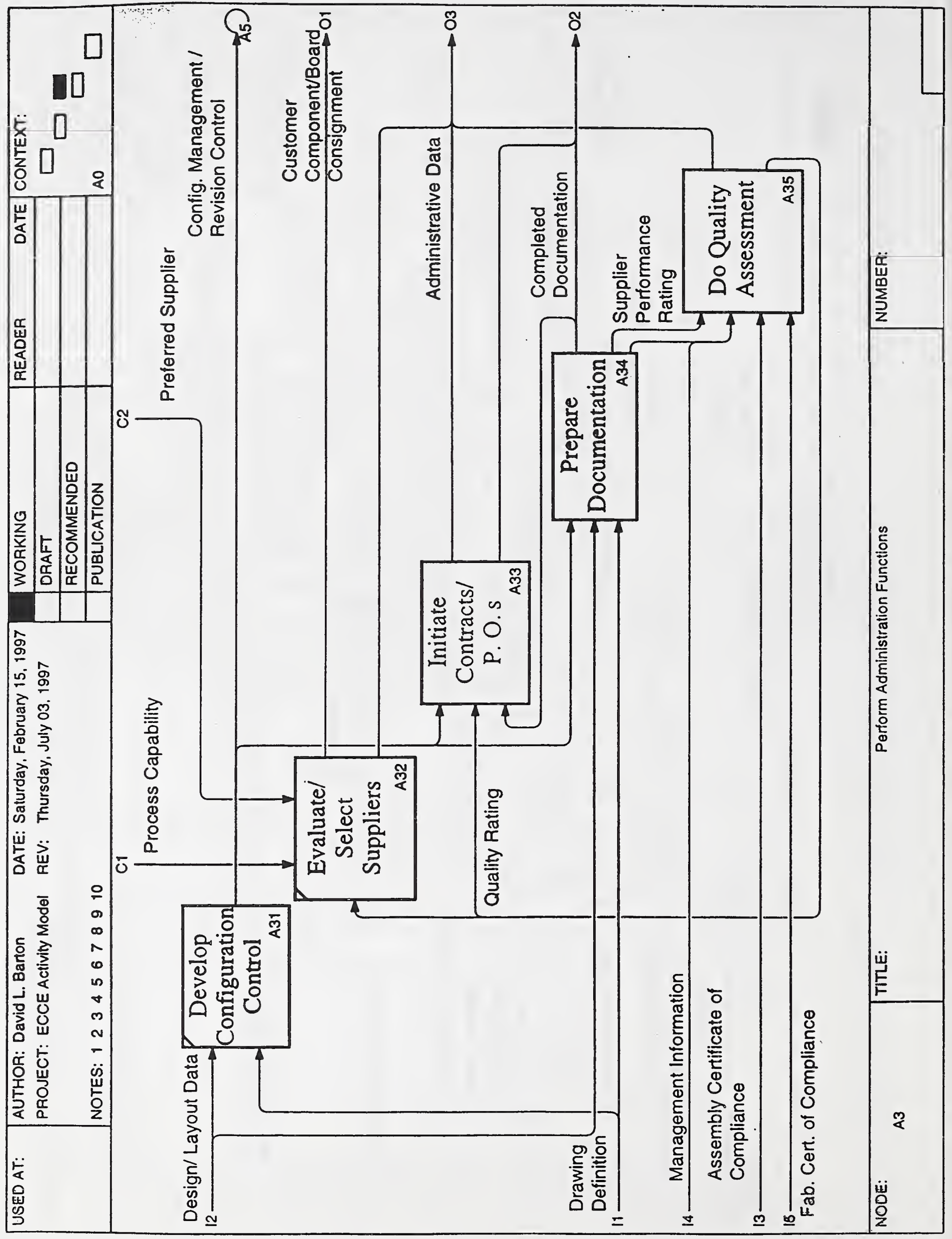




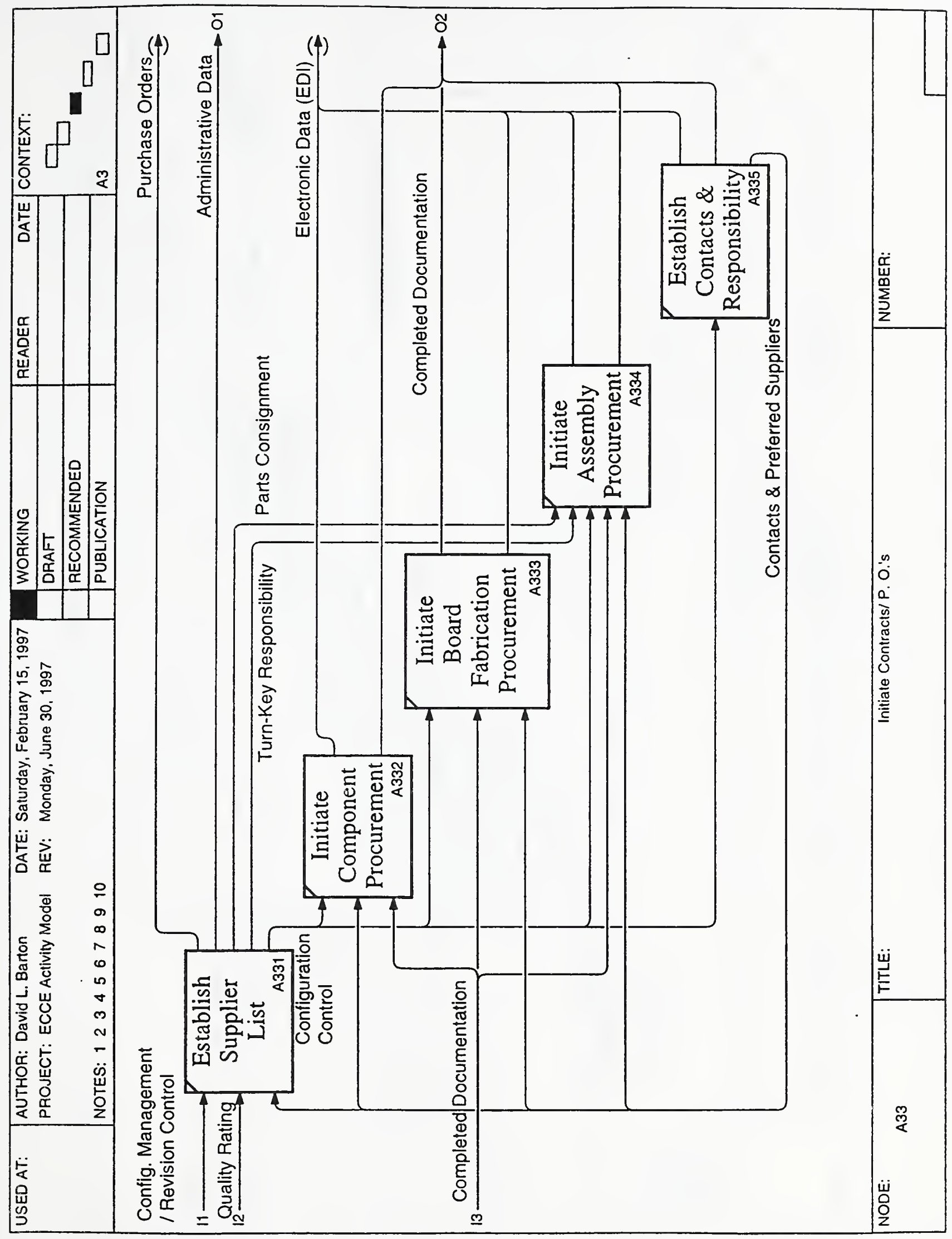




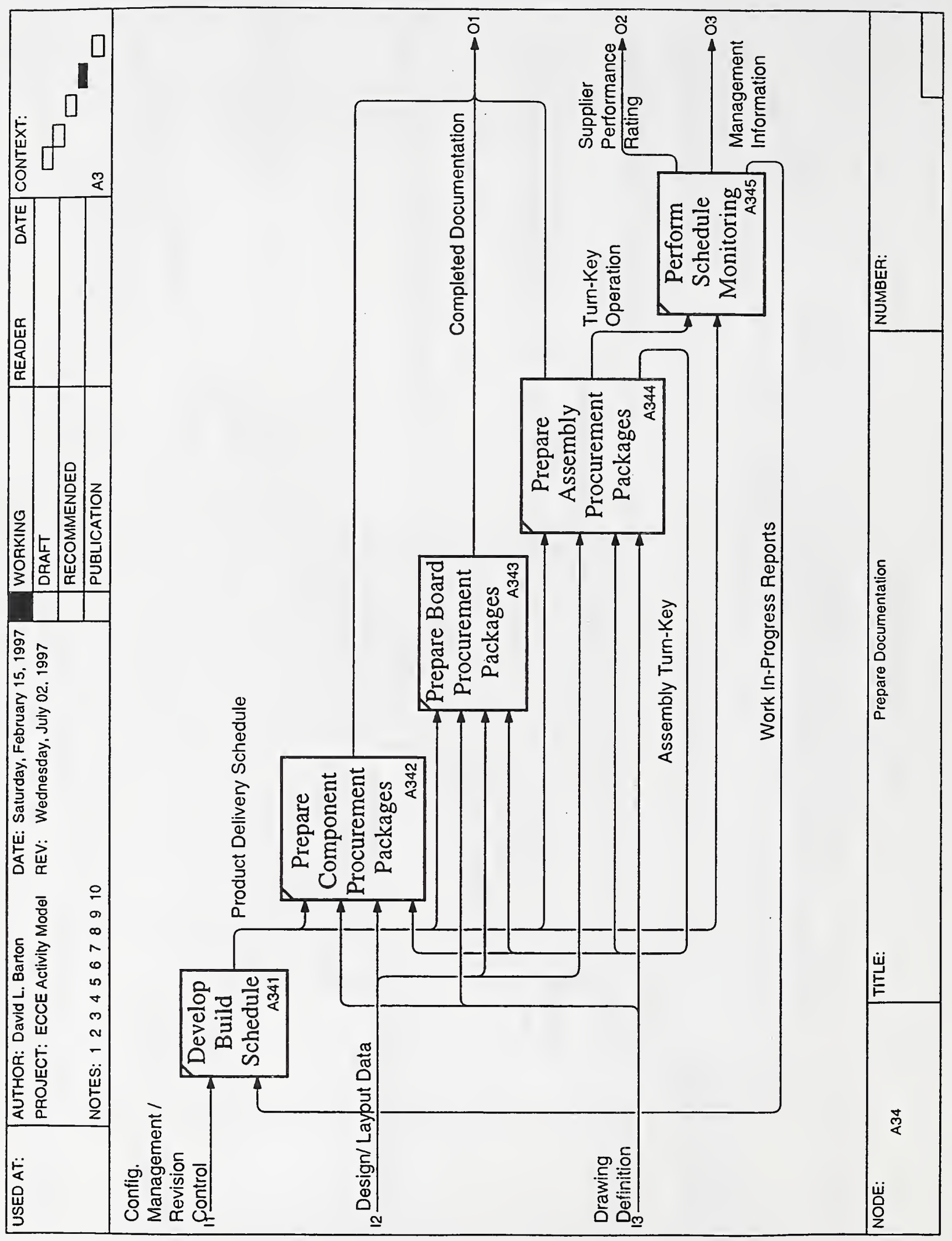




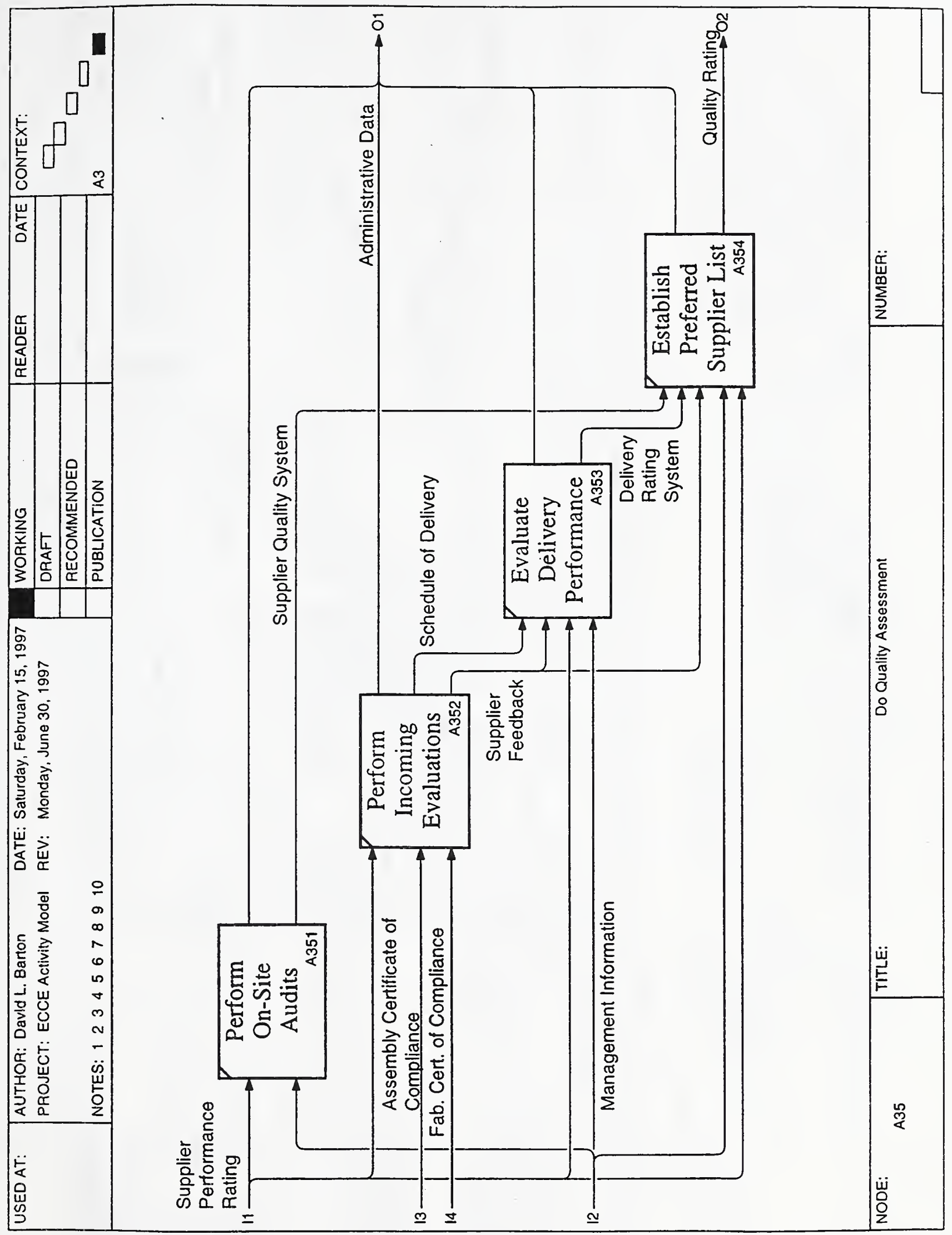




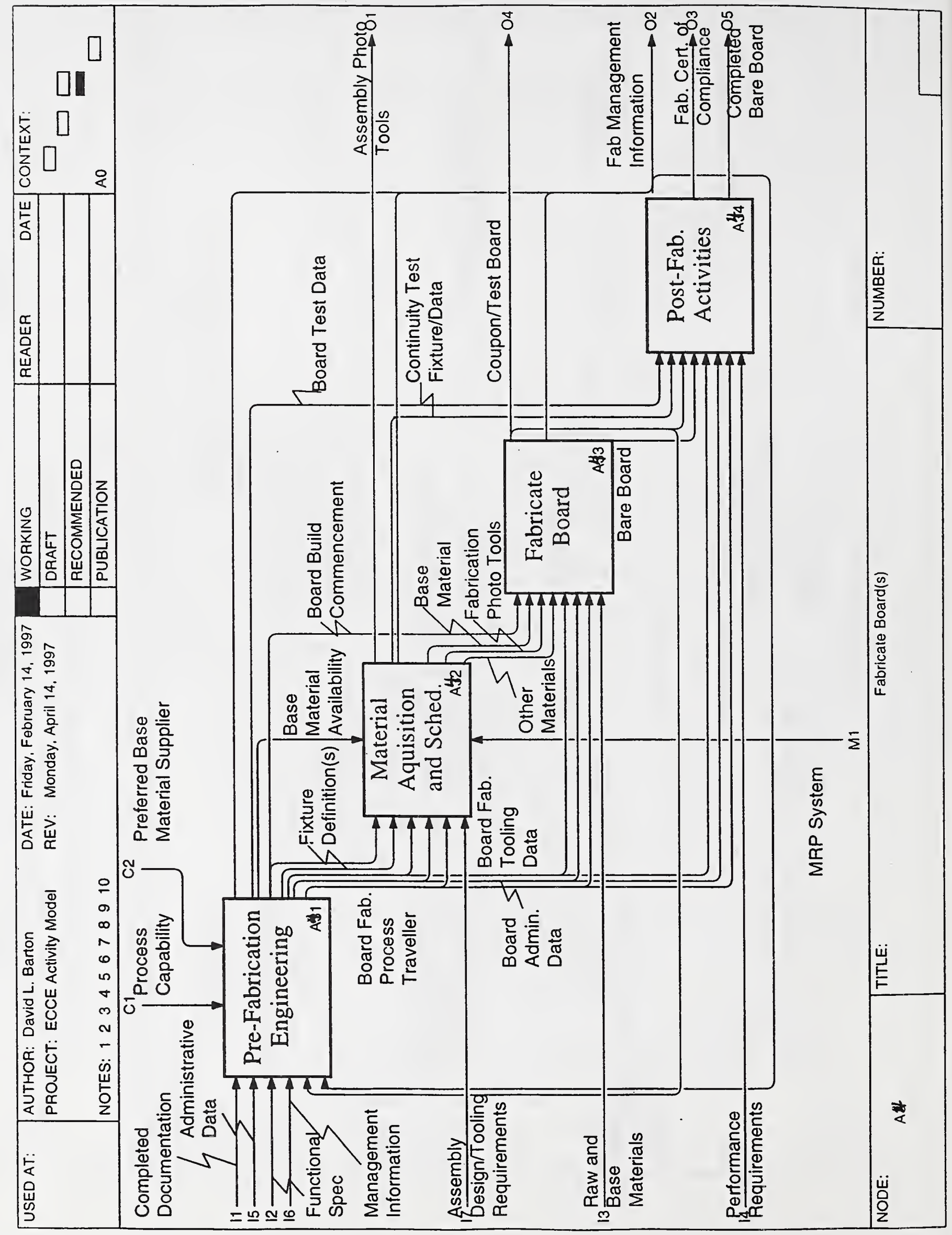




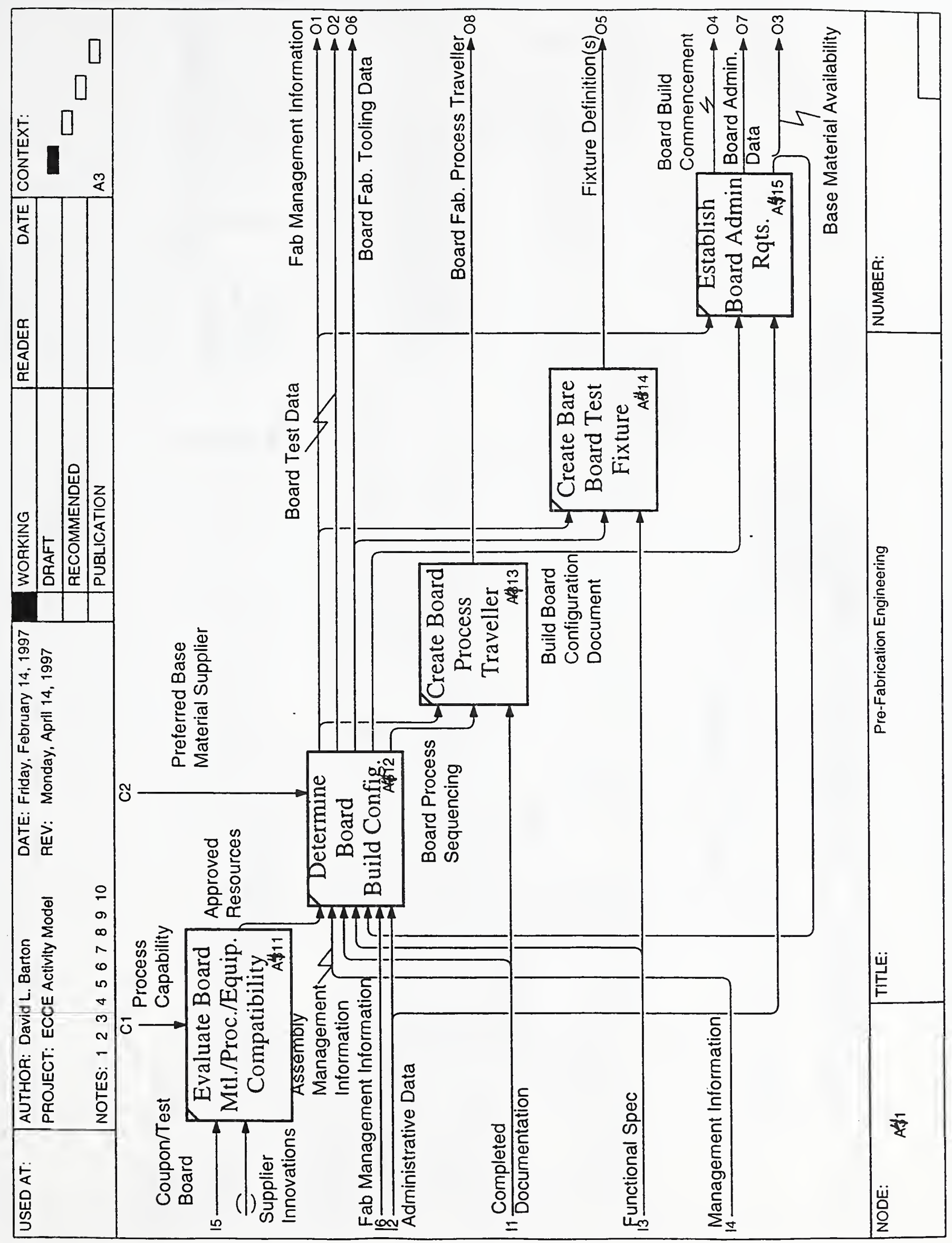




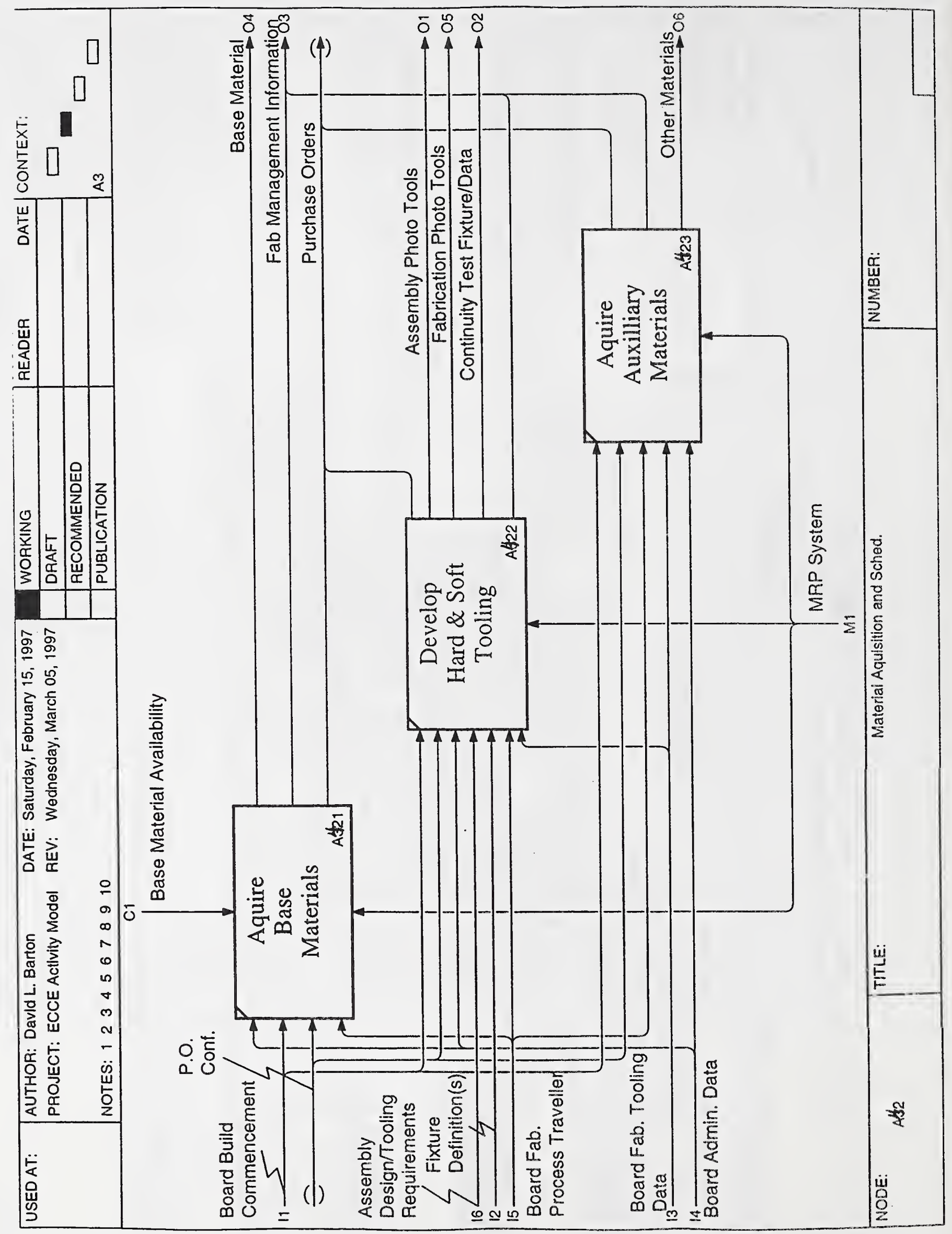




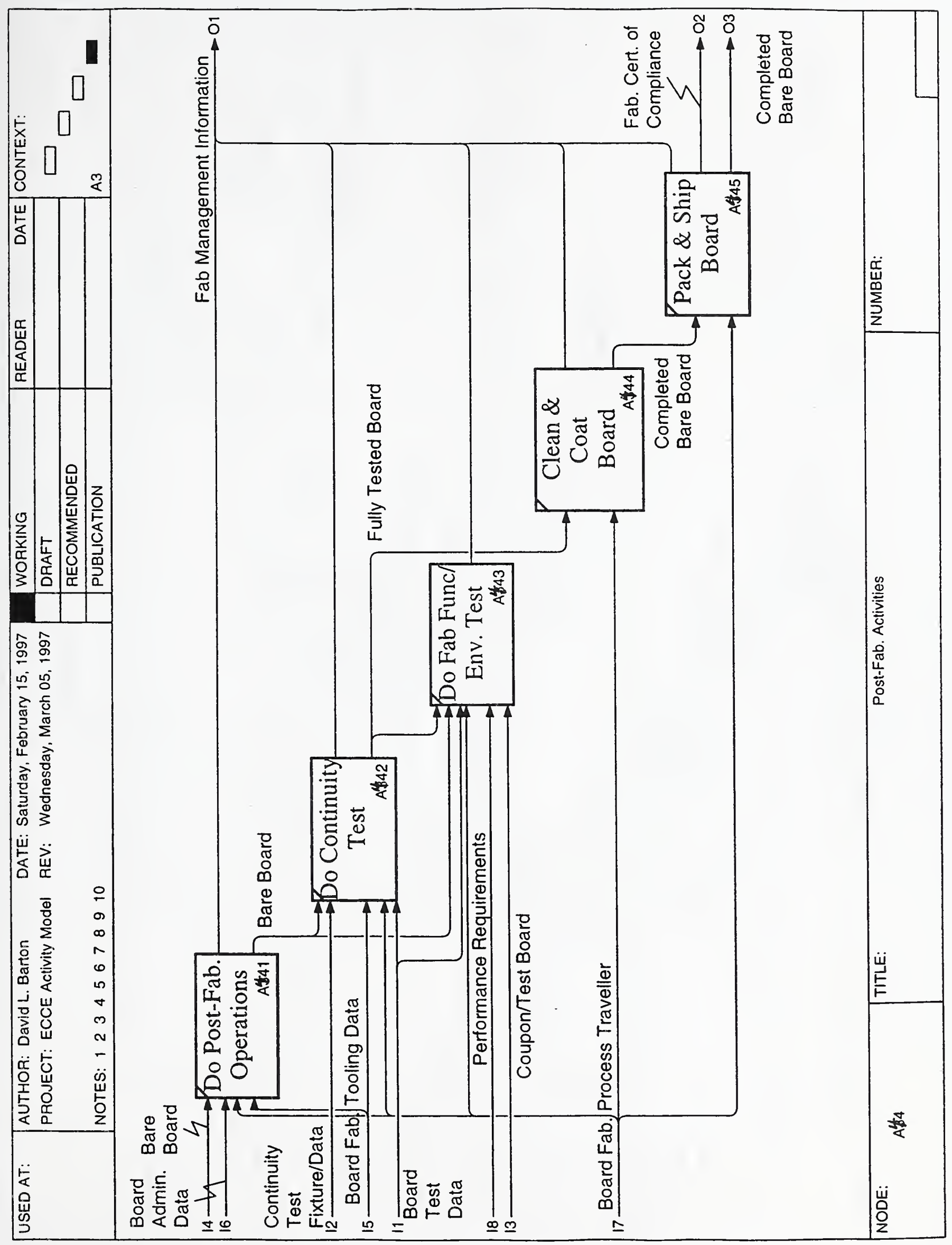




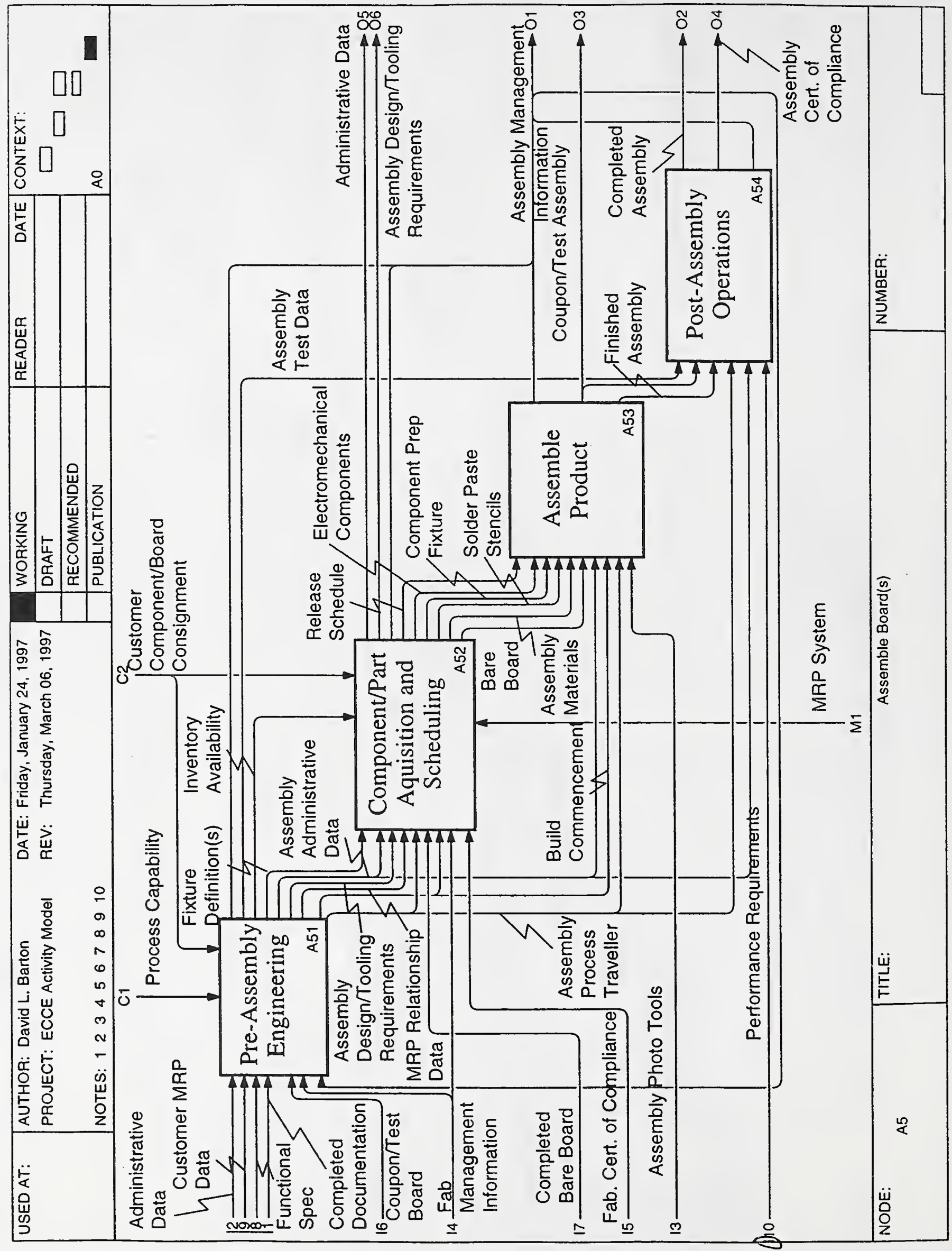




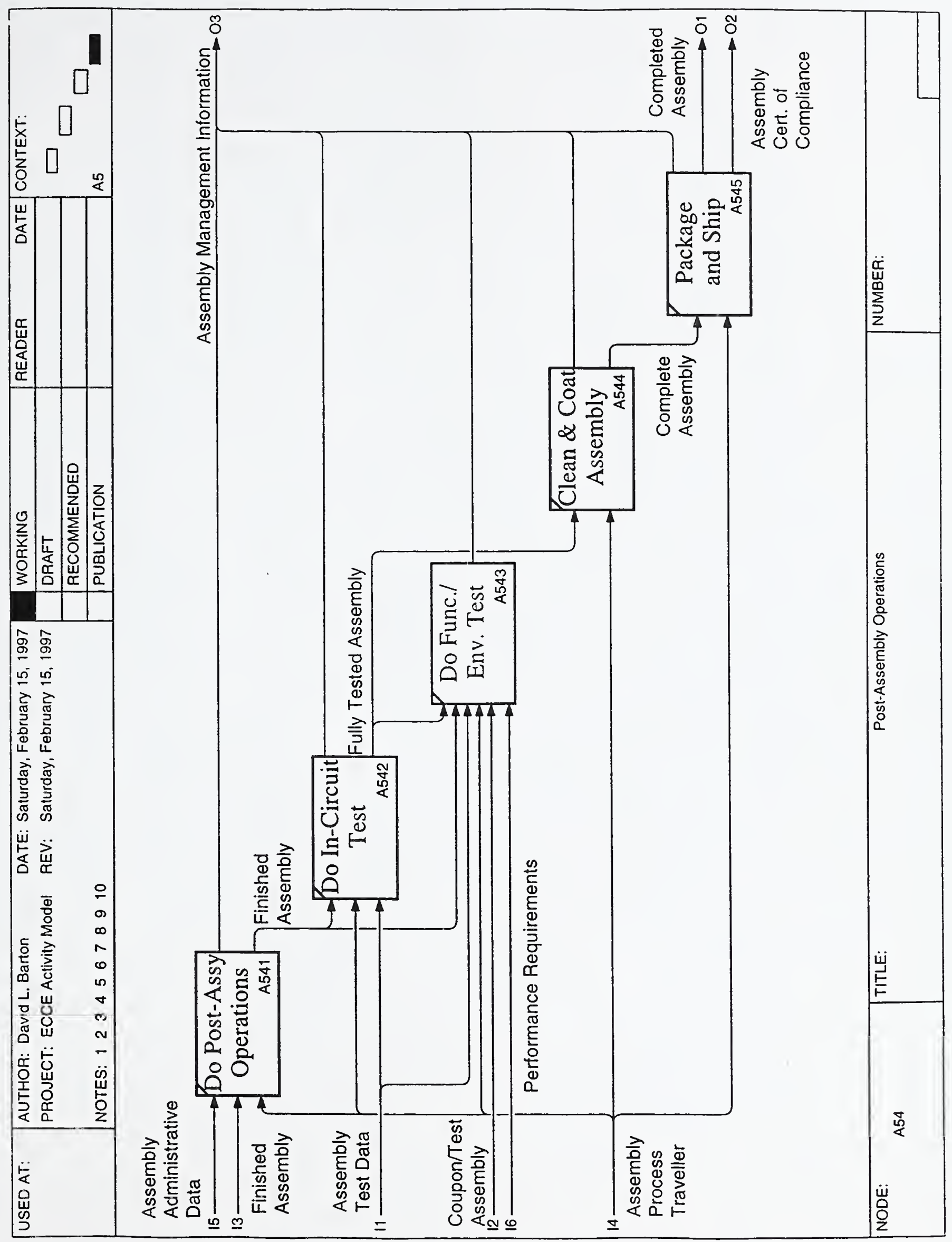


